
телей в деятельности библиотек (на примере Республиканского медицинского библиотечноинформационного центра)

Реферат. Сбалансированные системы показателей (ССП) широко применяются для достижения стратегических целей, обеспечения эффективной работы и успешного развития предприятий, учреждений и организаций. В многочисленных информационных источниках описаны различные подходы к их проектированию и созданные на базе этих подходов модели. Внедрение и последующее функционирование в Республиканском медицинском библиотечно-информационном центре (РМБИЦ) в Казани (Республика Татарстан) системы менеджмента качества обусловило потребность в такой ССП для учреждения, которая бы обеспечивала надлежащее качество его продукции и услуг. Однако, как показал анализ, проведенный по материалам публикаций, моделей, отражающих специфику библиотечно-библиографической и информационной деятельности и пригодных для практического использования, на данный момент не существует.

Была разработана концептуальная модель ССП, опираясь на мировой и собственный опыт и учитывая особенности сферы, в которой работает РМБИЦ. Раскрыты достоинства и недостатки ряда моделей и подходов к построению ССП, изложены основные положения и принципы проектирования концептуальной модели такой системы для библиотечно-библиографической и информационной деятельности. Высказано мнение, что синергетический подход позволяет создать модель, обеспечивающую тонкую и правильную настройку стратегии, формирование ключевых показателей эффективности, что способствует совершенствованию деятельности учреждения, занимающегося предоставлением библиотечно-библиографических и информационных услуг.

Представлена в графическом виде и подробно описана авторская концептуальная модель сбалансированной системы показателей, отвечающая потребностям РМБИЦ и логически вписывающаяся в систему управления учреждением, работающим в условиях непрерывно совершенствуемой системы менеджмента качества.

Ключевые слова: сбалансированная система показателей, модели, результативность библиотечноинформационной деятельности, стратегия развития библиотек, система менеджмента качества, Республиканский медицинский библиотечно-информационный центр.

Для цитирования: Дрешер Ю.Н., Косолапова Е.А. Построение модели сбалансированной системы показателей в деятельности библиотек (на примере Республиканского медицинского библиотечноинформационного центра) // Библиотековедение. 2018. T. 67, № 1. C. 23-31. DOI: 10.25281/0869608X-2018-67-1-23-31.
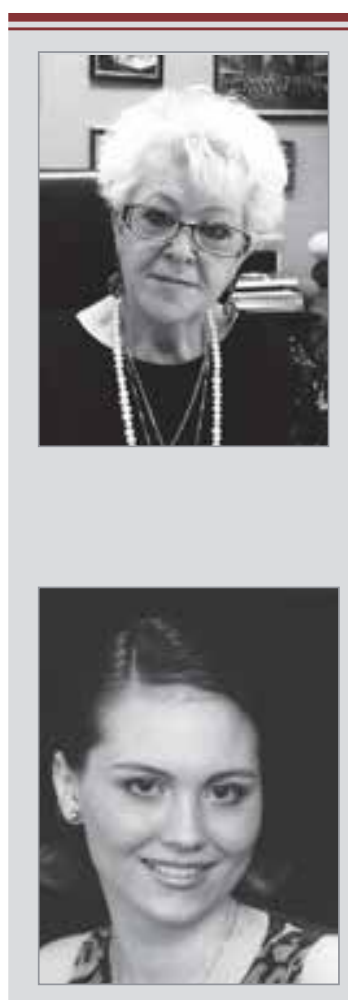

Евгения Александровна Косолапова, Республиканский медицинский библиотечно-информационный центр, отдел качества, заведующая сектором Хади Такташа ул., д. 125 , Казань, Республика Татарстан, 420059, Россия

E-mail: evgkvashnina@yandex.ru 
$\mathrm{K}$ ак известно, деятельность любого учреждения (организации), в том числе бюджетного, базируется на стратегии, миссии и видении. На этапе проектирования этой деятельности закладывается реализация стратегии развития. Для того чтобы стратегия работала, она должна быть:

- сфокусированной, т. е. вытекать из дерева целей организации, ее миссии, ценностей, видения, реализации видения (создание потенциала, определение условий и ограничений, достижение социальных целей), стоимостных и материальных целей;

- дифференцированной - направленной на достижение потребительских ценностей целевых сегментов пользователей, совершенствование продукции и/или освоение новых рынков;

- формализованной $[1 ; 2 ; 3$, с. $12 ; 4$, с. 85].

Существуют различные варианты реализации и контроля стратегии библиотек, но наиболее эффективный и распространенный из них - сбалансированная система показателей (ССП) [1; 5 , с. $167-168]$.

У каждого учреждения есть индикаторы, которые показывают, как и с какой скоростью организация добивается поставленных целей. Это и есть характерная черта ССП как стратегического инструмента.

Библиотеки, как и все другие организации, имеют свою стратегию и стратегические цели, но механизм их реализации на основе ССП для информационно-библиотечной деятельности, как показывают исследования, отсутствует. Это существенный пробел, поскольку ССП - стратегический инструмент, а также залог устойчивого развития информационно-библиотечной деятельности, который гарантирует оптимальную сбалансированность социальных, производственных, научно-практических факторов и компромисс между существующими приоритетами развития организации. Для разработки подходов к реализации стратегических целей, при которых может использоваться ССП, и обеспечения надлежащего качества информационно-библиотечной и библиографической продукции и услуг требуется анализ известных моделей ССП в условиях действующей системы менеджмента качества.

Рассмотрим модели ССП, авторами которых являются: Р. Каплан и Д. Нортон [6-10]; Х. Фридаг и В. Шмидт [11]; Н.-Г. Ольве, ЖЖ. Рой, М. Веттер [12]; Х. Рамперсад [13]; П.Р. Нивен [14; 15].

Многообразные проявления ССП базируются на шести составляющих, или компонентах: перспективы - элементы, обеспечивающие каскадирование стратегии; стратегические цели направления реализации стратегии; показате ли - параметры, отражающие текущее состояние определенных процессов деятельности организации, необходимые для достижения целей; целевые значения - количественные выражения показателей, которым они в идеале должны соответствовать к определенному времени; стратегическая карma - график, отражающий причинно-следственные связи между отдельными стратегическими целями; стратегические инициативы - проекты или программы, способствующие реализации выбранных ориентиров [6, с. $12 ; 7$, с. $3-12 ; 12$, с. $221 ; 14$, с. $117 ; 16$, с. $372 ; 17]$.

Именно для преобразования стратегии в действие мы используем сбалансированную систему показателей во всех ее проявлениях и формах.

Далее обозначим общие черты всех ССП [11, c. $83 ; 18]$ :

- главная стратегическая цель определяется миссией и видением;

- декомпозиция главной цели;

- ожидания различных заинтересованных сторон зависят от потенциала организации, направленного на реализацию основной цели;

- определение мероприятий и направлений действий, необходимых для достижения более мелких целей;

- для практического внедрения стратегии через проекты, программы и направления действий необходима организация совместной работы;

- инкорпорирование показателей в общую систему отчетности.

Существуют три критерия, определяющих различия в практическом применении ССП [11, c. $2-7]$.

1. Как ССП вписывается в стратегию учреждения? ССП - это не просто совокупность финансовых и нефинансовых коэффициентов, она должна отражать стратегию организации.

2. Каким образол производственные единииь вовлечены в разработку и внедрение стратегии?

3. Как ССП инкорпорируется в повседневную деятельность и отчетность организации? P.C. Каплан и Д.П. Нортон утверждают, что чем полнее сбалансированная система показателей интегрирована в общую систему управления и отчетности, тем успешнее происходит практическое перенесение стратегии учреждения в повседневную деятельность его клиентов, сотрудников и партнеров [6;9].

Суть подходов к ССП, а также сравнительная характеристика их моделей изложены в статье «Модели сбалансированной системы показателей: достоинства и недостатки» [19].

Подходы и модели ССП Р.С. Каплана и Д.П. Нортона [6, с. $13-15 ; 7$, с. $7-11 ; 8$, с. 4-9]; Х.Р. Фридага и В. Шмидта [11, с. 3]; Н.-Г. Ольве, ЗЖ. Роя и М. Веттера [12, с. 23-24]; Х.К. Рамперсада [13, с. 10]; П.Р. Нивена [14, с. 16-20] - это многоаспектные системы управления эффективностью деятельности учреждения, дающие возможность анализировать и регулировать наиболее важные стороны развития его деятельности и добиваться наилучшего результата по направлениям, обеспечивающим оправданные или превзойденные ожидания потребителей в отношении качества про- 
дукции и услуг, а также результативности работы и устранения возможных противоречий [20].

Проведенный анализ позволил сформулировать достоинства и недостатки основных моделей ССП с точки зрения разработки такой системы для организации с численностью сотрудников до 250 человек, не имеющей дочерних структур, производящей информационно-библиографическую и издательскую продукцию, предоставляющей информационно-библиотечные услуги в рамках государственного заказа (бюджетные организации) и работающей в условиях сертифицированной системы менеджмента качества (см. табл.).

Анализ рассмотренных моделей ССП показал, что для информационно-библиотечной деятельности наиболее подходит модель П.Р. Нивена, отличающаяся стратегической направленностью и потенциальной жизнеспособностью. Но, на наш взгляд, необходимо учесть достоинства и других моделей в частности тех из них, в которых делается акцент на интеллектуальном капитале персонала организации (концепция Х.Р. Фридага, В. Шмидта).

Поскольку при предоставлении информационно-библиотечной и библиографической услуги осуществляется межличностное и коммуникативное взаимодействие персонала с потребителем, необходимо выделить в отдельный блок оценки показателей эффективности управления сотрудниками организации так, как это предложил сделать в стратегических картах Л. Мейсель [21]. Следует учесть тот факт, что автор данного подхода предлагает включать инновации в человеческий капитал, а качество продукта - в проекцию бизнес-процессов. Тем не менее разумнее и реальнее выделить две различные перспективы: продукция и инновации; обучение и человеческий капитал.

\section{Достоинства и недостатки некоторых моделей (подходов к работе) сбалансированной системы показателей}

Таблица

\begin{tabular}{l} 
Достоинства \\
\hline \multicolumn{1}{|c|}{ Подход } \\
Формирование миссии, ви́дения, политики \\
в области качества и общекорпоративной си- \\
стемы показателей осуществляется в одно- \\
стороннем порядке высшим руководством \\
учреждения. Это отражает основную концеп- \\
цию ГОСТ Р ИСО 9001-2015 (раздел 5- «Ли- \\
дерство» и раздел 6- «Планирование») [20]. \\
Классическая ССП легко модифицируется \\
и может быть дополнена другими важны- \\
ми перспективами. Концентрированность \\
и качество представления информации по \\
выбранным перспективам
\end{tabular}

\section{Подход Х. Фридага и В. Шмидта}

Интеллектуальный капитал - в центре внимания

Движущей силой развития служит не финансовый капитал, а знания и умение их использовать

Не требуется иерархизация структур

Нет методических различий для сбалансированной системы показателей коммерческих и некоммерческих организаций

Необходимость обсуждать стратегические цели

Готовность разделить ответственность

Сбалансированное вовлечение всех действующих лиц

Достижение прозрачности благодаря показателям
Личные цели, как правило, не согласуются со стратегическими целями организации

Процессы в бюджетной Данный подход не даст для бюджеторганизации - не бизнес- ного учреждения положительных репроцессы, в ССП и прочих зультатов, особенно в условиях ориенновшествах персонал не за- тации организации на качество, здесь интересован ни в матери- необходима поддержка правительства альном, ни в социальном (местного, регионального, национальплане, так как все опреде- ного и т. п.) ляется бюджетом, за рамки которого организация выйти не может (отсюда и барьеры, и нежелание чтолибо изменять)

Концепция «открытых структур»

Личностная ССП не является основой для формирования ССП бюджетного учреждения

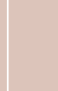

Противоречит формату бюджетной организации

Бюджетное учреждение работает по государственному заданию; кроме того, технологические процессы регламентированы, не допускают никакой самодеятельности и требуют измерения 
Окончание таблищь

\section{Подход Х. Рамперсада}

Систематические процессы непрерывного, Ориентация на финансо- Противоречит формату бюджетной последовательного и регулярного совер- вую составляющую дея- организации

шенствования, развития и обучения тесно тельности

связаны друг с другом. Это соответству- Формулирование личной Процедура является достаточно сложет требованию международного стандарта ССП сотрудников является ной и негибкой, не обеспечивает вы(раздел 7 - «Средства обеспечения» и раз- обязательной процедурой дел 10.3 - «Постоянное улучшение») [20] полнения миссии и достижения целей бюджетной организации

\section{Система сбалансированных показателей Д. Парментера}

Акцент на ключевых показателях эффек- Ориентация на финансо- Большое количество показателей тивности; четкое разделение показателей вую составляющую деярезультативности, производственных пока- тельности зателей каждого вида, направленных на формирование основных финансовых показателей деятельности

Модель стратегических карт Л. Мейселя

Выделение отдельной проекции трудовых Ориентация на финансо- Повышенная трудоемкость использоресурсов, включающей инновационную дея- вую перспективу органи- вания системы тельность, обучение и подготовку персонала, зации совершенствование продукции, формирование базисной компетенции фирмы и корпоративной культуры. Это соответствует положениям раздела 10.3 - «Постоянное улучшение», раздела 7.1.2 - «еловеческие ресурсы», раздела 7.2 - «Компетентность», раздела 8.6 «Выпуск продукции и услуг» [20]

ССП для государственных и неприбыльных организаций

\section{Подход П. Нивена}

Не берется в расчет: ин- Не соответствует требованиям раздетеллектуальный капитал лов 7.1.6 - «Знания организации»; организации, процесс не- $10-$ «Улучшение»; $7.2-$ «Компрерывного, последова- петентность»; 7.3 - «Осведомлентельного и регулярного ность» 9 - «Оценка результатов десовершенствования, раз- ятельности» [20] вития и обучения, четкое разделение показателей эффективности, результативности и производственных показателей

Рассмотренные модели - многоаспектные системы управления, которые позволяют отслеживать, анализировать и координировать особо важные направления развития и добиваться максимально возможного результата по направлениям, обеспечивающим ожидания потребителей (в нашем случае - читателей) в отношении качества продукции и услуг, а также устранять возникающие противоречия.

\section{Основные положения проектирования концептуальной модели ССп информа- ционно-библиотечной деятельности}

Необходимо дополнить проекцию «Потребитель» аспектом «Взаимоотношение с потребителями и партнерами» и ввести новые проекции - «Средства обеспечения и знания организации», «Процессы и система менеджмента качества», «Лидерство и приверженность высшего руководства совершенствованию и развитию». В проекции «Потребитель» следует рассматривать аспекты, связанные со стратегическими партнерами. Введение этих дополни- тельных проекций соответствует процессу обеспечения устойчивого развития учреждения, отражает его ориентацию на потребителя и формирование собственной базы знаний. Проекция «процессы и система менеджмента качества» связана с совершенствованием деятельности на основе менеджмента качества. Что касается финансовой составляющей, то в рамках статуса «бюджетное учреждение» нет возможности влиять на эту составляющую ССП, но тем не менее она не может быть исключена из рассмотрения проектируемой системы.

На наш взгляд, существует возможность построения специальной модели ССП для учреждения, осуществляющего информационно-библиотечную и библиографическую деятельность. Синергетический подход позволит создать необходимую модель, обеспечивающую тонкую и правильную настройку стратегии, формирование ключевых показателей эффективности - показателей достижения устойчивого успеха в деятельности или в реализации поставленных целей, определение целевых значений и инициатив, способствующих совершенствованию деятельности. 
Исходя из приведенных результатов анализа существующих моделей, предлагаем новую модель ССП Республиканского медицинского библиотечно-информационного центра (РМБИЦ) для государственного автономного учреждения. «Потенциал системы показателей по совершенствованию управления государственными и некоммерческими предприятиями еще выше (по сравнению с негосударственными коммерческими предприятиями)» [6, с. $236 ; 18]$. Очевидно, что государственные организации должны дополнить задачи стратегии в соответствии с целями высшего уровня, назначением этих организаций, планируемыми результатами. Кроме того, при разработке своей ССП, реализующей свою миссию, следует руководствоваться определенными принципами.

1. Миссия четко разграничивает государственные и частные организации: миссия государственной организации не может быть направлена на лиц, заинтересованных в ее финансовом успехе. Миссия РМБИЦ - обеспечение наивысшего качества и потребительской ценности информационно-библиотечных, библиографических продуктов и услуг, способствующих повышению профессионализма специалистов системы здравоохранения Республики Татарстан.

2. Необходимо обозначить стратегические цели в области качества. Главная стратегическая цель РМБИЦ - повышение показателей удовлетворенности пользователей библиотечной, библиографической и информационной продукцией и услугами до уровня 98,3\% и обеспечение наивысшего качества этих услуг по сравнению с другими организациями, предоставляющими продукцию для специалистов здравоохранения Республики Татарстан на основе международных систем менеджмента качества и лучших отечественных информационно-библиотечных технологий.

3. Наряду с миссией мы предлагаем выделить основные ценности, определяющие руководящие принципы для выполнения миссии, и ви́дение будущего. Ви́дение позволяет прогнозировать перспективу развития организации и определять переход от неизменных миссий и ценностей к динамичной и гибкой стратегии. Мы определили ви́дение и позиционируем себя в качестве профессиональной, инновационной и высокотехнологичной организации, ориентированной на полную удовлетворенность пользователей и занимающей ведущие позиции на всех уровнях - региональном, российском и международном.

4. Очень важно, чтобы миссия, видение, ценности и стратегические цели в области качества были доведены до каждого сотрудника организации и осознаны им. В РМБИЦ это осуществляется посредством проведения внутренних аудитов, семинаров и лекций.

5. Весьма существенным является принцип лидирующей роли руководства. Высшее руководство постоянно доводит до персонала информацию о важности результативного и эффективного менеджмента качества, обеспечения инкорпорированности менеджмента качества и ССП. Это делается на лекциях, в процессе проведения внутренних аудитов, на внутреннем сайте системы менеджмента качества.

6. Мотивация обязательно должна быть составляющей кадрового обеспечения любой государственной организации. В РМБИЦ персонал мотивируется, например, посредством прибавки дней к основному отпуску при условии отсутствия больничных листов в течение всего года, что регламентировано коллективным договором РМБИЦ.

Таким образом, на основании данных принципов и разделов стандартов ГОСТ Р ИСО 9001-2015 [20] и ГОСТ Р ИСО 9004-2010 [22] нами разработана концептуальная модель сбалансированной системы показателей информационно-библиотечной и библиографической деятельности (см. рис.).

В центре концептуальной модели ССП информационно-библиотечной и библиографической деятельности РМБИЦ располагается стратегия, которая касается общих приоритетов, направленных на выполнение заданной миссии. Эти приоритеты должны соответствовать уникальному положению организации на рынке и быть взаимосвязанными.

Стратегическое направление или проекция «Потребитель/пользователь» располагается в верхней части сбалансированной системы показателей, поэтому, как и вся информационно-библиотечная и библиографическая деятельность нашей организации, направлена не на получение финансовой прибыли, а на обеспечение высокого качества продукции, услуг и удовлетворенности ими потребителя/пользователя.

Следующая проекция - «Лидерство и приверженность высшего руководства». Иными словами, как высшее руководство демонстрирует свое лидерство и приверженность в системе менеджмента качества.

Сбалансированную систему показателей нельзя считать полной без проекции «Финансы». В модели ССП для государственного сектора финансовые показатели рассматриваются как движущие силы успешного обслуживания потребителей и как ограничения, в рамках которых должна работать организация.

Далее следует проекция «Система менеджмента качества и процессы». Стратегия организации в сбалансированной системе показателей заключается в отборе и оценке именно тех процессов, которые ведут к большей удовлетворенности запросов потребителей/пользователей, а в итоге позволяют повысить качество предоставляемой продукции и услуги.

Проекция «Средства обеспечения» - это наличие ресурсов, необходимых для разработки, внедрения, поддержания и постоянного улучшения системы менеджмента качества, направленной на обеспечение выполнения требований потребителей/ 


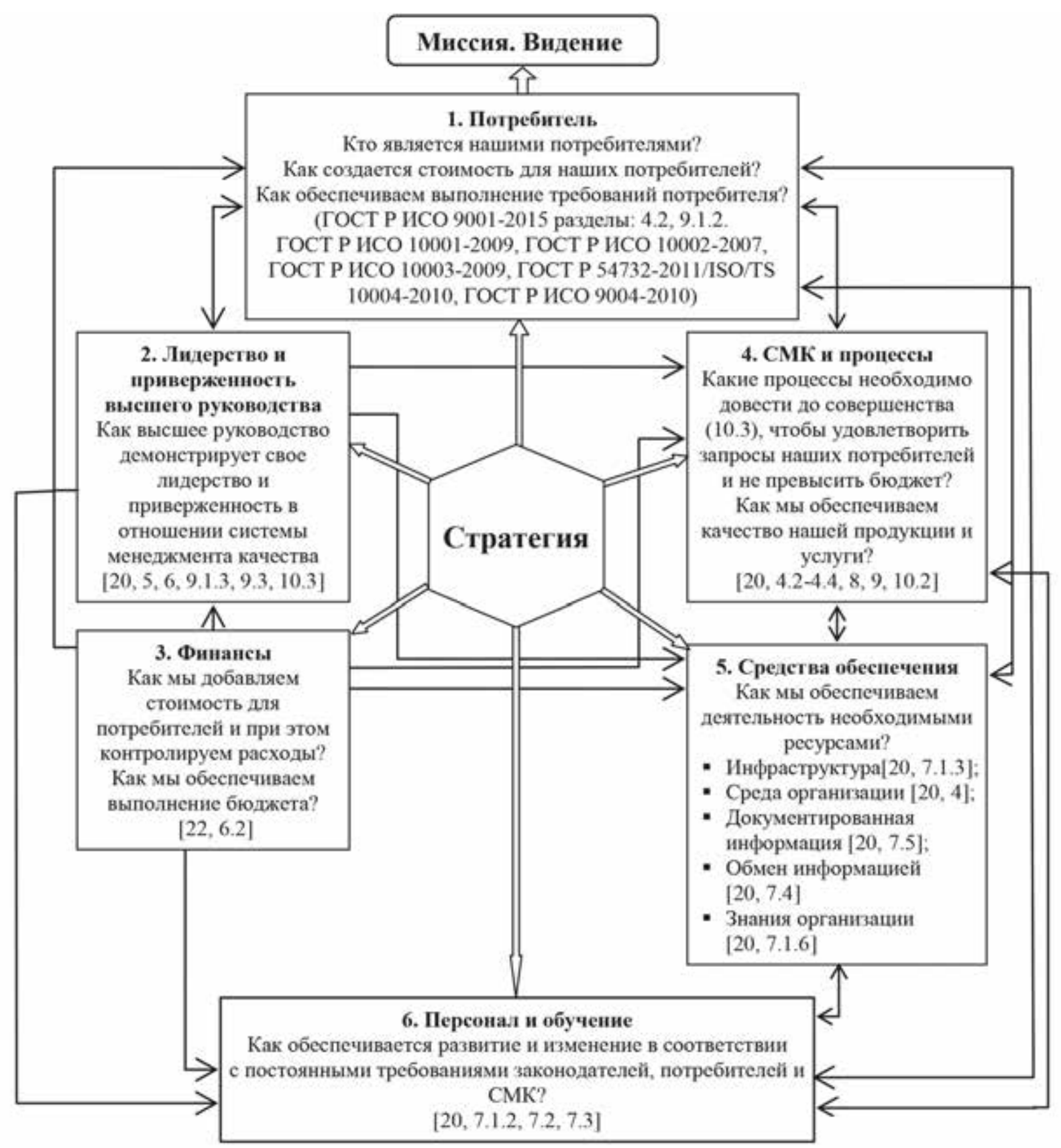

Кониептуальная модель сбалансированной систелы показателей инфорлационно-библиотечной и библиографической деятельности РМБИЦ

пользователей и повышение их удовлетворенности.

Последняя проекция - «Персонал и обучение». Результативность функционирования процессов зависит от персонала организации и уровня его профессиональной подготовки, компетентности, осведомленности, что достигается внедрением соответствующих процессов обучения, обеспечивающих достижение устойчивого успеха организации на рынке информационно-библиотечных и библиографических услуг и продукции.

Необходимо учитывать, что без мониторинга, анализа и оценки деятельности учреждения невозможно реализовать его стратегию. Выбор методики мониторинга имеет большое значение для обеспечения надлежащей результативности процесса измерения и анализа.

В процессе принятия стратегических и тактических решений важно в полной мере учитывать факторы, которые влияют на достижение успеха учреждения. Эти факторы необходимо измерять. Они не могут противоречить стратегическим целям учреждения, миссии, видению, политике в области качества. Необходимо также принимать в расчет возможности и риски. 


\section{Список источников}

1. Герасилов Е.Ю., Русин А.Н. Сбалансированная система показателей как инструмент реализации стратегии [Электронный ресурс] // Группа компаний «Волгасофт» : сайт. URL: http://www.m-bo.ru/ artifull.php?ELEMENT_ID=198 (дата обращения: 01.02.2018).

2. Пашанин И. Сбалансированная система показателей как основа стратегического управления [Электронный ресурс] // Консалтинговая компания iTeam : сайт. URL: http://iteam.ru/publications/ strategy/section_27/article_3220 (дата обращения: 01.02.2018).

3. Кох Р. Стратегия: основы стратегического мышления и пошаговые инструкции по разработке и реализации стратегических планов. Москва: Эксмо, 2007. $212 \mathrm{c}$.

4. Квашнина E.A. Система сбалансированных показателей как основа стратегического управления информационно-библиотечной деятельностью // Инновационная деятельность библиотек в контексте новой общественной реальности: проблемы, практика, перспективы : материалы науч.-практ. конф., Казань, 25 ноября 2016 г. / под ред. А.С. Трудовой, С.А. Семенычевой. Казань : КГМУ, 2017. С. 84-94.

5. Джумиго Н.А. Концепция сбалансированной системы показателей как важнейший элемент управления [Электронный ресурс] // Известия Алтайского государственного университета. 2009. № 2. C. 167-172. URL: https://cyberleninka.ru/article/n/ kontseptsiya-sbalansirovannoy-sistemy-pokazateleykak-vazhneyshiy-element-upravleniya (дата обращения: 01.02.2018).

6. Каплан Р.С., Нортон Д.П. Сбалансированная система показателей : от стратегии к действию. 2-е изд., испр. и доп. Москва : Олимп-Бизнес, 2008. 320 с.

7. Измерение результативности компании : пер. с англ. 2-е изд. Москва : Альпина Бизнес Букс, 2007. 220 с.

8. Разработка сбалансированной системы показателей: практ. руководство с примерами / под ред. А.М. Гершуна, Ю.С. Нефедьевой. 2-е изд., расшир. Москва : Олимп-Бизнес, 2007. 128 с.

9. Каплан Р.С., Нортон Д.П. Организация, ориентированная на стратегию. Москва : Олимп-Бизнес, 2004. $514 \mathrm{c}$.

10. Каплан Р.С., Нортон Д.П. Стратегические карты. Трансформация нематериальных активов в материальные результаты : пер. с англ. Москва : ОлимпБизнес, 2005. 512 c.

11. Фридаг Х.Р., Шмидт В. Сбалансированная система показателей / [пер. с нем. М.В. Лапшинова]. Москва : Омега-Л, 2006. 144 с.
12. Ольве Н.-Г., Рой Ж., Веттер М. Оценка эффективности деятельности компании : практическое руководство по использованию сбалансированной системы показателей. Москва : Вильямс, 2004. 304 с.

13. Ралперсад X.К.Универсальная система показателей деятельности: как достигать результатов, сохраняя целостность. 3-е изд. Москва: Альпина Бизнес Букс, 2006. $352 \mathrm{c}$.

14. Нивен П.Р. Сбалансированная система показателей для государственных и неприбыльных организаций / под ред. О.Б. Максимовой. Днепропетровск : Баланс Бизнес Букс, 2005. 336 с.

15. Нивен П.Р. Сбалансированная система показателей - шаг за шагом. Максимальное повышение эффективности и закрепление полученных результатов. Москва : Баланс-клуб, 2003. 328 с.

16. Внедрение сбалансированной системы показателей / Horvath \& Partners ; [науч. ред. В. Толкач] ; [пер. с нем. В. Толкача, С. Данишевич, М. Гавриша]. 2-е изд. Москва : Альпина Бизнес Букс, 2006. 478 с.

17. Косолапова E.A. Анализ проекций сбалансированной системы показателей. Эффективные системы менеджмента: качество, инновации, устойчивое развитие : материалы VI Международного науч.практ. форума (16-18 февраля 2017 г., Казань). Ч. 1 / под ред. И.И. Антоновой. Казань : Познание, 2017. С. 236-242.

18. Никифорова Е., Резникова Н. Система сбалансированных показателей: интегрированный менеджмент // Проблемы теории и практики управления. 2006. № 3. С. $46-53$.

19. Дрешер Ю.Н., Квашнина Е.А. Модели сбалансированной системы показателей: достоинства и недостатки / / Внедрение системы менеджмента качества в деятельность библиотек - главное условие достижения устойчивых конкурентных преимуществ : сб. науч. тр. Казань : Медицина, 2016. С. 159-174.

20. ГОСТ Р ИСО 9001-2015. Системы менеджмента качества. Требования [Электронный ресурс] // Кодекс : законодательство, комментарии, консультации, судебная практика : сайт. URL: http://docs.cntd.ru/ document/1200124394 (дата обращения: 01.02.2018).

21 Maisel L.S. Performance Measurement. The Balanced Scorecard Approach // Journal of Cost Management, Summer, 1992. P. 47-52.

22. ГОСТ Р ИСО 9004-2010. Менеджмент для достижения устойчивого успеха организации. Подход на основе менеджмента качества [Электронный ресурс] // Кодекс : законодательство, комментарии, консультации, судебная практика : сайт. URL: http://docs.cntd.ru/document/1200082555 (дата обращения: 01.02.2018). 


\title{
To the Question of the Balanced Scorecard System Modelling in the Context of Libraries (Using the Example of the Republican Medical Library-Information Center)
}

\author{
Julia N. Dresher*, Evgenia A. Kosolapova**, \\ Republican Medical Library-Information Center, 125 Khadi Taktash Str., Kazan, 420059 Republic of \\ Tatarstan, Russia \\ E-mail: "dresher07@yandex.ru, "*evgkvashnina@yandex.ru
}

\begin{abstract}
Balanced scorecard (BSC) is widely used to achieve strategic objectives, ensure the efficient operation and successful development of enterprises, institutions and organizations. Multiple information sources describe different approaches to BSC design and models created on the basis of these approaches. Introduction and subsequent functioning of the Quality management system in the Republican Medical Library-Information Center (RMLIC) in Kazan (Republic of Tatarstan) has led to the need for such BSC in the institution, which would have ensured the proper quality of its products and services. However, the analysis of publications revealed the absence of the models for bibliographic and information activities suitable for practical use at the moment.

It was decided to develop the conceptual model of BSC, basing on the international and own experience and considering specific features of RMLIC area. The article describes the advantages and disadvantages of a number of models and approaches to the construction of BSC, the basic provisions and main principles of designing conceptual model of such system for bibliographic and information activities. The opinion is expressed that synergetic approach allows to create a model, providing fine and well-tuned strategy, formation of key performance indicators that contributes to improve the activities of institution engaged in the provision of library-bibliographic and information services.

The author's conceptual model of the balanced scorecard is presented graphically and described in detail. It meets the needs of RMLIC and logically fits into the control system of the institution operating in the conditions of continuous improvement of the Quality management system.
\end{abstract}

Key words: Balanced Scorecard System, Models, Library-Information Activity Performance, Library Development Strategy, Quality Management System, Republican Medical Library-Information Center.

Citation: Dresher J.N., Kosolapova E.A. To the Question of the Balanced Scorecard System Modelling in the Context of Libraries (Using the Example of the Republican Medical Library-Information Center), Bibliotekovedenie [Library and Information Science (Russia)], 2018, vol. 67, no. 1, pp. 23-31. DOI: 10.25281/0869-608X-2018-67-1-23-31.

\section{References}

1. Gerasimov E.Yu., Rusin A.N. Balanced Scorecard as a Tool of Strategy Implementation, Gruppa kompanii "Volgasoft": sait [Group of Companies "Volgasoft": website]. Available at: http://www.m-bo.ru/artifull. php?ELEMENT_ID=198 (accessed 01.02.2018), (in Russ.).

2. Pashanin I. Balanced Scorecard as a Basis for Strategic Management, Konsaltingovaya kompaniya iTeam: sait [iTeam Consulting Company: website]. Available at: http://iteam.ru/publications/strategy/ section_27/article_3220 (accessed 01.02.2018), (in Russ.).

3. Koch R. Strategiya: osnovy strategicheskogo myshleniya i poshagovye instruktsii po razrabotke i realizatsii strategicheskikh planov [Strategy: Fundamentals of Strategic Thinking and Step-by-Step Instructions for Developing and Implementing Strategic Plans]. Moscow, Eksmo Publ., 2007, 212 p.

4. Kvashnina E.A. Balanced Scorecard as a Basis for Strategic Management of Information and Library Activities, Innovatsionnaya deyatel'nost' bibliotek $v$ kontekste novoi obshchestvennoi real'nosti: problemy, praktika, perspektivy: materialy nauch.-prakt. konf., Kazan', 25 noyabrya 2016 g. [Proceedings of the Sci.Prac. Conf. "Innovative Activities of Libraries in the Context of New Social Reality: Problems, Practice, Prospects" (Kazan, November 25, 2016)]. Kazan, KGMU Publ., 2017, pp. 84-94 (in Russ.).

5. Dzhumigo N.A. The Concept of Balanced Scorecard as a Basic Element of Management, Izvestiya 
Altaiskogo gosudarstvennogo universiteta [News of the Altai State University], 2009, no. 2, pp. 167172. Available at: https://cyberleninka.ru/ article/n/kontseptsiya-sbalansirovannoy-sistemypokazateley-kak-vazhneyshiy-element-upravleniya (accessed 01.02.2018), (in Russ.).

6. Kaplan R.S., Norton D.P. The Balanced Scorecard: Translating Strategy into Action. Moscow, OlimpBiznes Publ., 2008, 320 p. (in Russ.).

7. Izmerenie rezul'tativnosti kompanii [Measuring the Effectiveness of Company]. Moscow, Al'pina Biznes Buks Publ, 2007, 220 p.

8. Gershun A.M., Nefedyeva Yu.S. (eds). Razrabotka sbalansirovannoi sistemy pokazatelei: prakt.rukovodstvo s primerami [Developing a Balanced Scorecard: practical guide with examples]. Moscow, Olimp-Biznes Publ., 2007, 128 p.

9. Kaplan R.S., Norton D.P. The Strategy-Focused Organization. Moscow, Olimp-Biznes Publ., 2004, 514 p. (in Russ.).

10. Kaplan R.S., Norton D.P. Strategy Maps: Converting Intangible Assets into Tangible Outcomes. Moscow, Olimp-Biznes Publ., 2005, 512 p. (in Russ.).

11. Friedag H.R., Schmidt W. Balanced Scorecard. Moscow, Omega-L Publ., 2006, 144 p. (in Russ.).

12. Olve N.-G., Roy J., Wetter M. Performance Drivers: A Practical Guide to Using the Balanced Scorecard. Moscow, Vil'yams Publ., 2004, 304 p. (in Russ.).

13. Rampersad H.K. Universal System Performance: How to Achieve Results While Maintaining Integrity. Moscow, Al'pina Biznes Buks Publ., 2006, 352 p. (in Russ.).

14. Niven P.R. Balanced Scorecard Step-by-Step for Government and Nonprofit Agencies. Dnepropetrovsk, Balans Biznes Buks Publ., 2005, 336 p. (in Russ.).

15. Niven P.R. Balanced Scorecard Step-by-Step - Maximizing Performance and Maintaining Results. Moscow, Balans-Klub Publ., 2003, 328 p. (in Russ.).

16. Tolkach V. (ed.) Vnedrenie sbalansirovannoi sistemy pokazatelei [Implementation of the Balanced Scorecard]. Moscow, Al'pina Biznes Buks Publ., 2006, 478 p.
17. Kosolapova E.A. Analiz proektsii sbalansirovannoi sistemy pokazatelei. Effektivnye sistemy menedzhmenta: kachestvo, innovatsii, ustoichivoe razvitie. Materialy VI Mezhdunarodnogo nauch.-prakt. foruma (16-18 fevralya 2017 g., Kazan') [Proceedings of the 6th Int. Sci.-Prac. Forum "Analysis of the Balanced Scorecard Projections. Effective Management Systems: Quality, Innovation, Sustainable Development" (February 16-18, 2017, Kazan)], Part 1. Kazan, Poznanie Publ., 2017, pp. 236-242.

18. Nikiforova E., Reznikova N. The System of Balanced Indicators: Integrated Management, Problemy teorii $i$ praktiki upravleniya [Theoretical and Practical Aspects of Management], 2006, no. 3, pp. 46-53 (in Russ.).

19. Dresher Yu.N., Kvashnina E.A. Balanced Scorecard Models: Advantages and Disadvantages, Vnedrenie sistemy menedzhmenta kachestva $v$ deyatel'nost' bibliotek - glavnoe uslovie dostizheniya ustoichivykh konkurentnykh preimushchestv: sb. nauch. tr. [Implementation of the Quality Management System in Libraries Is the Main Condition for Achieving Sustainable Competitive Advantages: collected scientific papers]. Kazan, Meditsina Publ., 2016, pp. 159-174 (in Russ.).

20. GOST R ISO 9001-2015. State Standard R ISO 90012015. Quality Management Systems. Requirements, Kodeks: zakonodatel'stvo, kommentarii, konsul'tatsii, sudebnaya praktika: sait [Legal Information Consortium "Kodeks": website]. Available at: http:// docs.cntd.ru/document/1200124394 (accessed 01.02.2018), (in Russ.).

21 Maisel L.S. Performance Measurement. The Balanced Scorecard Approach, Journal of Cost Management, Summer, 1992, pp. 47-52.

22. GOST R ISO 9004-2010. State Standard R ISO 90042010. Managing for the Sustained Success of an Organization. A Quality Management Approach, Kodeks: zakonodatel'stvo, kommentarii, konsul'tatsii, sudebnaya praktika: sait [Legal Information Consortium "Kodeks": website]. Available at: http://docs.cntd. $\mathrm{ru} /$ document/1200082555 (accessed 01.02.2018), (in Russ.). 